\title{
Environmental Health Perceptions in University Classrooms: Results From an Online Survey During the COVID-19 Pandemic in the United States and Colombia
}

\author{
Maria Camila Coronado ${ }^{1 *}$, Siobhan Rockcastle ${ }^{2}$ and Alison Kwok ${ }^{1}$ \\ ${ }^{1}$ NetZED Laboratory, School of Architecture \& Environment, University of Oregon, Eugene, OR, United States, ${ }^{2}$ Baker Lighting \\ Lab, School of Architecture \& Environment, University of Oregon, Eugene, OR, United States
}

OPEN ACCESS

Edited by:

Francesco Salamone, National Research Council of Italy, Italy

Reviewed by:

Ludovico Danza,

Istituto per le Tecnologie della Costruzione, Consiglio Nazionale delle

Ricerche (CNR), Italy Matteo Ghellere,

Istituto per le Tecnologie della Costruzione, Consiglio Nazionale delle Ricerche (CNR), Italy

*Correspondence: Maria Camila Coronado mcorona6@uoregon.edu

Specialty section: This article was submitted to

Indoor Environment,

a section of the journal Frontiers in Built Environment

Received: 28 September 2021 Accepted: 02 December 2021

Published: 24 December 2021

Citation:

Coronado MC, Rockcastle $S$ and Kwok A (2021) Environmental Health Perceptions in University Classrooms: Results From an Online Survey During the COVID-19 Pandemic in the United States and Colombia. Front. Built Environ. 7:784634. doi: 10.3389/fbuil.2021.784634
At the start of the COVID-19 pandemic, multiple institutions mobilized to create recommendations that maximize indoor environmental quality to keep building occupants as safe as possible. Many of those recommendations were implemented in buildings across the world even before the presence of field data validated their effectiveness. However, as the pandemic raised awareness of the risks present in the air quality of everyday built environments, little is known about how occupants perceive these interventions or how they will perceive buildings when activities resume with an inperson requirement. This paper presents results from an online survey, conducted from April 23rd to May 8th, 2021, and offers a window into the perceptions of university students on a variety of physical intervention strategies that have been promoted for the return to classrooms. Our analysis explores differences in these perceptions between students from Colombia and the United States, where the vaccination rates of the population as of May 2021 differed substantially. An anonymous online survey was disseminated to students of higher academic institutions using images portraying 3D models of classrooms and written prompts to assess perceptions. Health risk and health promotion perceptions were evaluated using four categories: visual connection to the outdoors, occupant density, additional furnishings, ventilation system type, and number of operable windows. While the effectiveness of these strategies from an epidemiological standpoint was not considered, this survey aimed to measure the perceived effectiveness of these strategies as students prepare to return to in-person education in the classroom. Our analysis found a significant effect of different degrees of "connection to the outdoors" and "occupant density" on both perceived health risk and health promotion in both countries. Respondents ranked strategies like mask-wearing and natural ventilation as important interventions when considering a return to the classroom. Perceptions of health risk and health promotion between students taking classes in the United States and Colombia were significantly different regarding the presence of additional furnishings, and ventilation systems and number of windows in a classroom. The results presented here may shed light on how 
aspects of the built environment help shape perceptions of healthy environments during the pandemic.

Keywords: health risk perceptions, COVID-19, indoor environmental quality, university classrooms, healthy buildings

\section{INTRODUCTION}

People living in the United States spend over $90 \%$ of their time inside buildings (Klepeis et al., 2001), which is similar to what happens in other cities around the world. Buildings mediate access to the outdoors and can have profound impacts on human health. The COVID-19 pandemic created a unique set of circumstances that raised public awareness about the importance of creating healthy indoor environments to prevent the transmission of disease. While past research has explored the impact of buildings on human physiology (stress, arousal, and circadian health), the concept of health goes beyond physical wellbeing. Health has been defined by the World Health Organization as the as "a state of complete physical, mental and social wellbeing” (World Health Organization, 2006), which includes social and psychological aspects that complete the human experience.

In the built environment, Indoor Environmental Quality (IEQ) describes the quality of environmental variables that can drive the health and wellbeing of building occupants (Centers for Disease Control and The National Institute for Occupational Safety and Health, 2013). IEQ includes many aspects of the indoor environment, such as light, acoustics, thermal comfort, indoor air quality, interior design, water quality, spatial configuration, and their social and psychological impacts (Awada et al., 2021). Until recently, research on health in the built environment generally focused on limiting exposure risk, by studying the impact of building form on Sick Building Syndrome (SBS) or discomfort. More recent approaches strive to create conditions that measure the promotion of wellbeing, considering building performance, perception, and occupant behavior to provide opportunities for positive health outcomes (Amundadottir et al., 2017; Altomonte et al., 2020; Danell et al., 2020).

During the COVID-19 pandemic, building scientists have been especially concerned with providing suitable physical conditions to create safe spaces for people (Megahed and Ghoneim, 2020). Experts have placed most of their attention on ventilation systems and how they affect transmission. Improving building HVAC operation can reduce the potential spread of SARS-CoV-2 by increasing outdoor air exchange rates but can also result in unintended consequences, like higher energy consumption and more frequent maintenance. Inadequate management of an HVAC system could even increase disease transmission potentials through air recirculation, and other considerations like ventilation sources, natural ventilation, air distribution, daylight and electric lighting, the effects of air distribution and lighting on viruses and microbial communities, as well as spatial strategies to promote social distancing should be included as well (Dietz et al., 2020).
At the time of our survey (April/May 2021), it had been over a year since the start of the COVID-19 pandemic. In many places around the world, the increase in vaccination rates had encouraged governments, businesses, and schools to explore the potential for returning to in-person activities. Professional organizations and academic institutions had issued guidelines for systems and spaces during the pandemic. The United States Center for Disease Control (CDC) used the Hierarchy of Controls (National Institute for Occupational Safety and Health National Institute for Occupational Safety and Health, 2015) to reduce health hazards in school settings. This framework allows for the prioritization of protective measures against environmental hazards in five levels, from most effective to least effective. These measures are Elimination, Substitution, Engineering controls, Administrative controls, and Personal protective equipment (PPE) (National Institute for Occupational Safety and Health National Institute for Occupational Safety and Health, 2015). Efforts related to the operation and use of buildings fall in the three lower categories (National Academies of Sciences Engineering and Medicine, 2020). Regarding engineering controls, detailed guidelines for the operation of HVAC systems to reduce concentrations of infectious aerosols were developed by organizations like ASHRAE (ASHRAE, 2020).

Various reports on reopening schools from 2020 enumerated a series of recommendations to achieve indoor environmental quality (J. Allen et al., 2020; ASHRAE, 2020; Centers for Disease Control, 2020; Jones et al., 2020; National Academies of Sciences Engineering and Medicine, 2020). Among these strategies were ventilation, air filtration, additional air purifiers, temperature and symptom screening, use of masks, frequent hand washing and respiratory etiquette, using transparent screens between desks, maximizing physical distancing, eliminating large gatherings, disinfecting objects after each use, and contact tracing in combination with isolation and quarantine (Centers for Disease Control, 2020; Healthy Buildings and Harvard T.H Chan School of Public Health, 2020; Jones et al., 2020; National Academies of Sciences Engineering and Medicine, 2020). Despite these guidelines, enforcement of the recommended measures varies in schools across the country, as the pandemic and our understanding of transmission risk continues to evolve.

Most schools that have returned to in-person education have implemented a combination of these general recommendations. A survey from 41 school districts in the United States asked respondents to rate 6 Indoor Air Quality (IAQ) approaches to help reduce COVID-19 transmission. The strategies were higher grade MERV filters, air cleaners with EPA filters, increase outdoor air supply via HVAC system, open windows, fan in doors \& windows to increase exhaust, and pre/post occupancy 
flushing. They found that mechanical ventilation strategies geared towards increasing fresh air intake were the most highly prioritized, followed by air filtration strategies, while operable windows were the least prioritized strategies (The Center for Green Schools and ASHRAE, 2021).

Despite the lowered risk of transmission in the vaccinated age groups, people may still feel that a return to in-person activities in schools and universities is not completely safe. A survey with 2,000 undergraduates from 120 colleges from March 2021 found that about half of the respondents were anxious to return to inperson classes (Ezarik, 2021). Similarly, partial results of a parent survey of the same month by Los Angeles Unified Students found that about half the students would not be returning to campus. Students in communities with high death rates from the virus still felt wary of going back to the classroom (Blume, 2021).

Contextual differences such as vaccination rates, local daily cases, building ventilation practices and systems, and implementation of virus mitigation strategies might influence variations in perceptions of risk in the built environment. This paper aims at studying these differences by looking at student perceptions in the United States and Colombia. According to data published by the World Coronavirus Vaccine Database, by May $13,2021,46.23 \%$ of people in the United States had received at least one dose of the COVID-19 vaccine, while in Colombia, only $8.55 \%$ of the population had received it (Ritchie et al., 2021). In addition, the two countries have different norms for the use of mechanical ventilation. In the United States, air conditioning systems have been widespread for decades and are well established in the building stock (International Energy Agency, 2018), while in Colombia air conditioning is still a growing market (International Energy Agency, 2017; JRAIA, 2019). Compared to the seasonal climate that happens in the United States, Colombia is a tropical country that does not experience seasons, so most buildings are naturally ventilated.

The COVID-19 pandemic raised awareness about the risks of poor indoor air quality in everyday built environments. Risk perception is shaped by the risk environment to which an individual is exposed (Han et al., 2021). Reducing perceptions of unnecessary risk may mitigate emotional distress (Han et al., 2021), which could, in turn, contribute to better mental and social wellbeing. Different frameworks have been developed to perform risks and benefits analysis in other fields. Using the psychometric paradigm, these frameworks have looked at perceived risks, acceptable risks, and perceived benefits using questionnaire techniques (Fischhoff et al., 1978). This approach might be useful to assess perceptions of health risks and health promotion in the built environment for the post-pandemic world. However, as universities plan to reopen, little is known on how students will perceive classrooms when activities resume to an in-person format.

This paper acts as a snapshot in time between April 23rd to May 8th' 2021, and explores university student's perceptions of different physical intervention strategies that have been promoted for the return to classrooms. The paper considers the perceptions of health risks, health promotion and importance from students in the United States and Colombia and explores their differences within and between countries. While the effectiveness of these strategies from an epidemiological standpoint was not considered, this survey aimed to measure the perceived effectiveness of these strategies as students prepare to return to in-person education in the classroom.

\section{METHODS}

This pilot study is based on an online survey that gathered responses from students taking classes in the United States and Colombia. The survey was translated to both English and Spanish and disseminated to students in higher education institutions of the United States and Colombia, through email, listserve, and social media. Responses were received between April 23rd to May 8th, 2021.

The survey was comprised of 20 sets of questions. The first ten questions were demographic and aimed at characterizing the participants regarding age, sex, type of student (Full-time, parttime, less than part time, other), degree program, type of degree program (undergraduate, graduate, $\mathrm{PhD}$, other), country of origin, field of study, current location, country where they were taking classes, and whether they had returned to inperson activities or not. The following eight questions were organized to assess student's perceptions on health risks and health promotion, given a range of physical intervention strategies for healthy buildings issued during the pandemic. A last set of questions assessed students' perceived importance of eight given intervention strategies. Finally, an open-ended question asked participants to leave additional commentaries for the development of the survey.

To assess health risks and health promotion perceptions, a series of plain rendered images were used to portray 3D models of classroom scenarios containing different physical features that were grouped by category. Considering a selection of strategies recommended for in-person classrooms during the pandemic, four categories of intervention were defined: 1) Visual connection to the outdoors, 2) Reduced occupancy, 3) Additional furnishings, and 4) Ventilation type and number of windows. For each category in the survey, an image depicted a particular situation, followed by a sentence that explained the strategy depicted in the image to clarify any confusion about the difference between images (Figure 1).

For the visual connection to the outdoors category, respondents were presented with three classroom scenarios using mechanical ventilation and filtration but with a different number of fixed windows. The scenarios were named as follows: (A) two fixed windows, (B) one fixed window, (C) no windows. For the reduced occupancy category, participants were presented with three images displaying a classroom occupied to (D) $1 / 2$ of its capacity, (E) 1/3 of its capacity, and (F) 1/4 of its capacity. For the additional furnishings category, respondents were presented with three classrooms where an additional piece of furniture related to the safety measures that emerged during the pandemic was added to the room. In scenario $(G)$, a hand sanitizer station was placed in front of the classroom, scenario $(\mathrm{H})$ featured an additional air purifier, and scenario (I) presented transparent screens on each desk. For both reduced occupancy and additional 


\section{Visual connection to the outdoors}

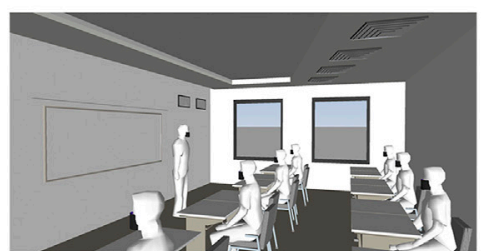

A

This classroom has TWO FIXED windows and MECHANICAL VENTILATION and FILTRATION.

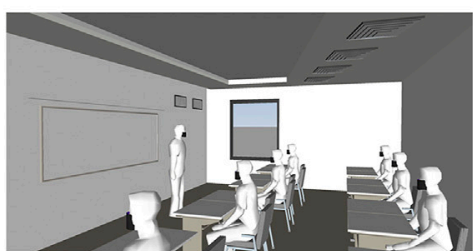

B window and MECHANICAL VENTILATION and FILTRATION.

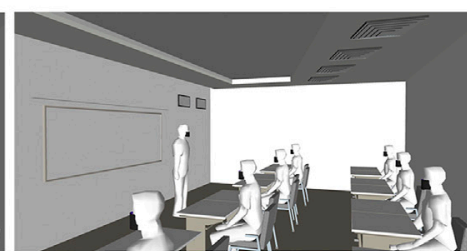

C This classroom has NO windows and MECHANICAL VENTILATION and FILTRATION.

\section{Reduced occupancy}

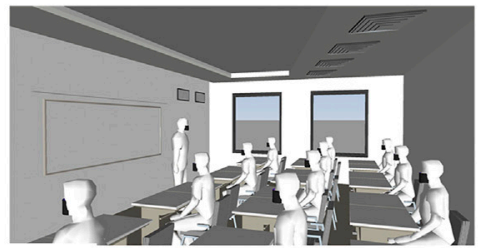

D This classroom is occupied to $1 / 2$ of its full capacity

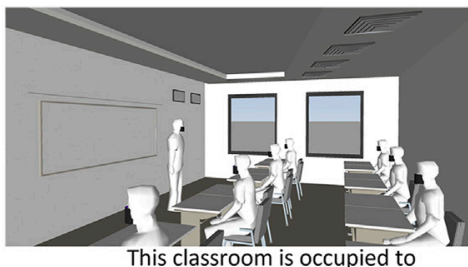

E $1 / 3$ of its full capacity

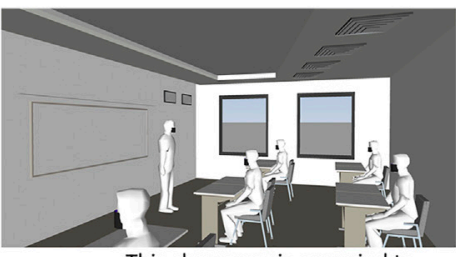

F $\quad 1 / 4$ of its full capacity

\section{Additional furnishings}

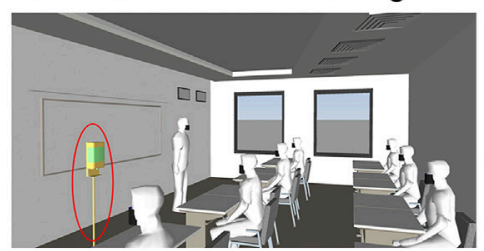

G This classr

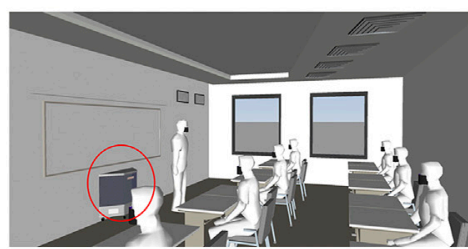

H This classroom has an AIR PURIFIER

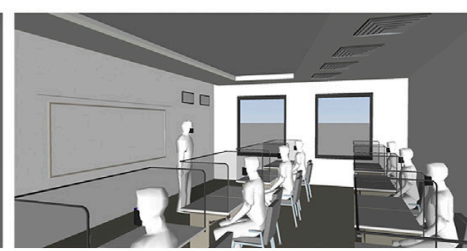

This classroom has TRANSPARENT SCREENS in each desk

\section{Ventilation type and number of windows}

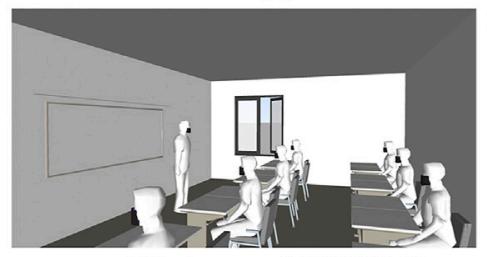

This classroom is NATURALLY

$\mathbf{J}$

VENTILATED and has ONE

operable window

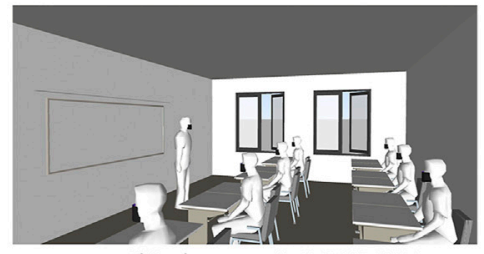

This classroom is NATURALLY

L VENTILATED and has TWO

operable windows

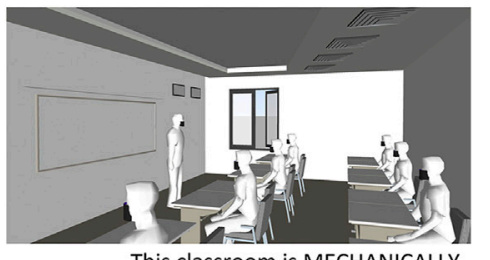

This classroom is MECHANICALLY

K

OEATED and has ONE

operable window

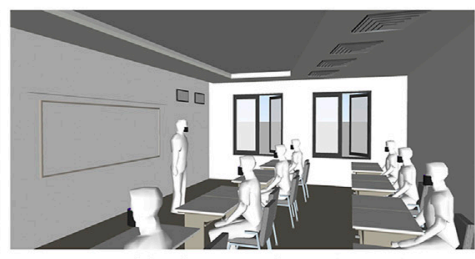

This classroom is MECHANICALLY

M VENTILATED and has TWO operable windows

FIGURE 1 | Renderings presented to the participants in the survey to assess risk perception and health promotion in classrooms. Scenarios (A-C) portray variations of visual connections to the outdoors. Scenarios (D-F) portray variations of reduced occupancy. Scenarios (G-I) portray variations of additional furnishings. Scenarios (J-M) portray variations of ventilation type and number of windows. 


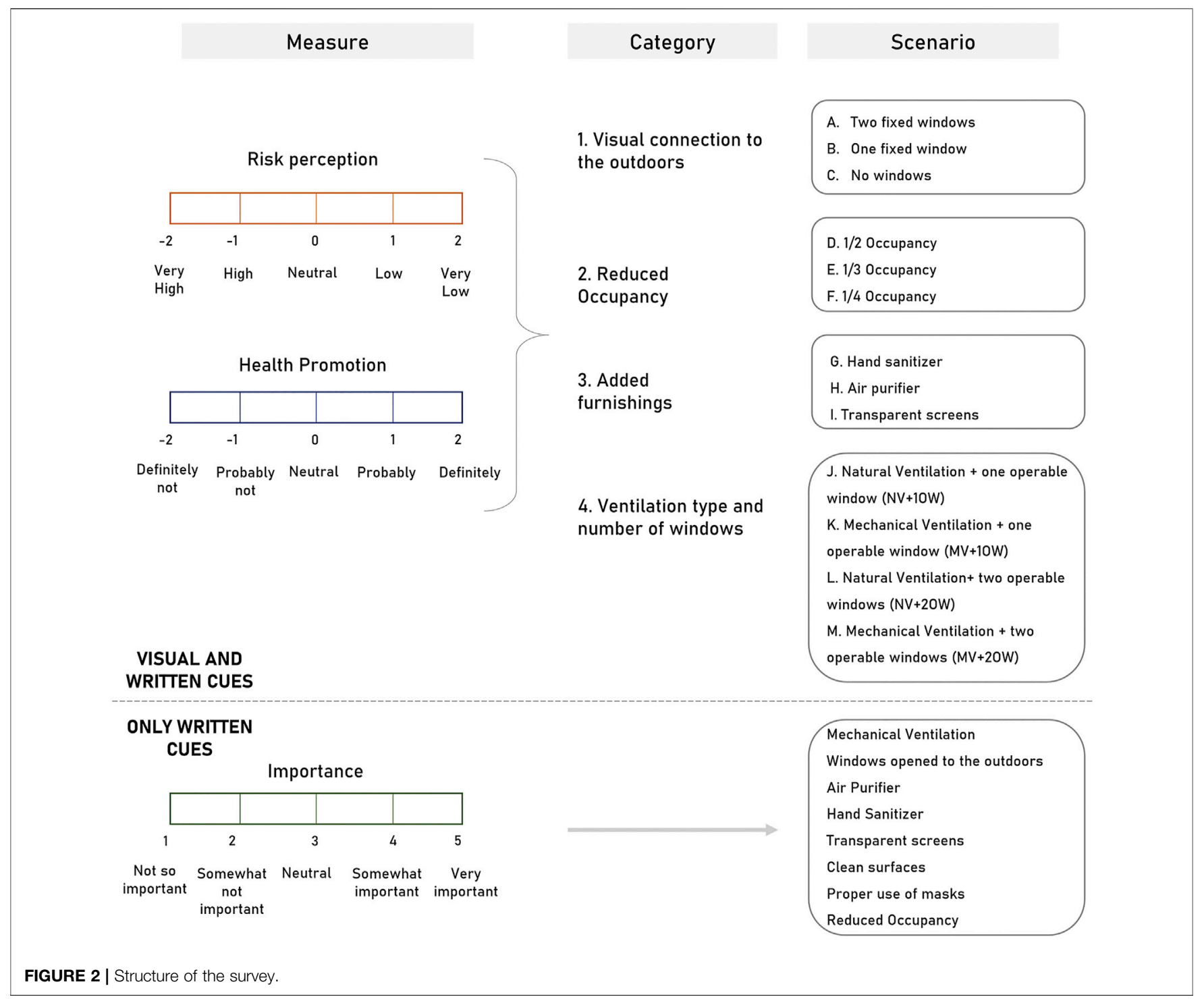

furnishings all classrooms featured the same mechanical ventilation strategies and two windows but did not specify the type of ventilation. Finally, for the ventilation type and number of windows category, respondents were presented with scenarios where the number of windows and ventilation types changed. Scenario $(\mathrm{J})$ presented a classroom with natural ventilation $(\mathrm{NV})$ and one operable window (OW) opened to the outdoors. Scenario (K) featured a classroom with one operable window but added visible features of mechanical ventilation (MV). Scenarios (L) and (M) both presented two windows opened to the outdoors and different types of ventilation. Scenario (L) featured natural ventilation, while scenario $(\mathrm{M})$ showed additional features of mechanical ventilation. As in the previous categories, all images had a prompt next to them clearly explaining the differences between each scenario.

Following the images, respondents were presented with 2 fivepoint Likert scale questions that evaluated their perceptions of health risk and health promotion in each classroom scenario. For health risk perceptions, the scale ranged from: very high, high, neutral, low, and very low, and was coded $(-2,-1,0,1,2)$, following the same order for the analysis. For health promotion, the scale ranged from: definitely not, probably not, neutral, probably, and definitely, and was coded $(-2,-1,0,1,2)$, following the same order. In both cases, negative scores represent undesirable situations, and positive scores represent desirable situations.

To assess the importance respondents placed on each strategy, a five-point Likert scale was used to rate a set of eight hazard mitigation strategies related to classrooms' physical features. For this last set of questions, respondents were not presented with an image. Nonetheless, the strategies were closely related to the previous four scenarios and were defined as follows: 1) robust mechanical ventilation, 2) windows opened to the outdoors, 3) additional air purifiers, 4) presence of hand sanitizer, 5) transparent screens on each desk, 6) clean surfaces, 7) people wearing masks, and 8) reduced occupancy. Like the previous 


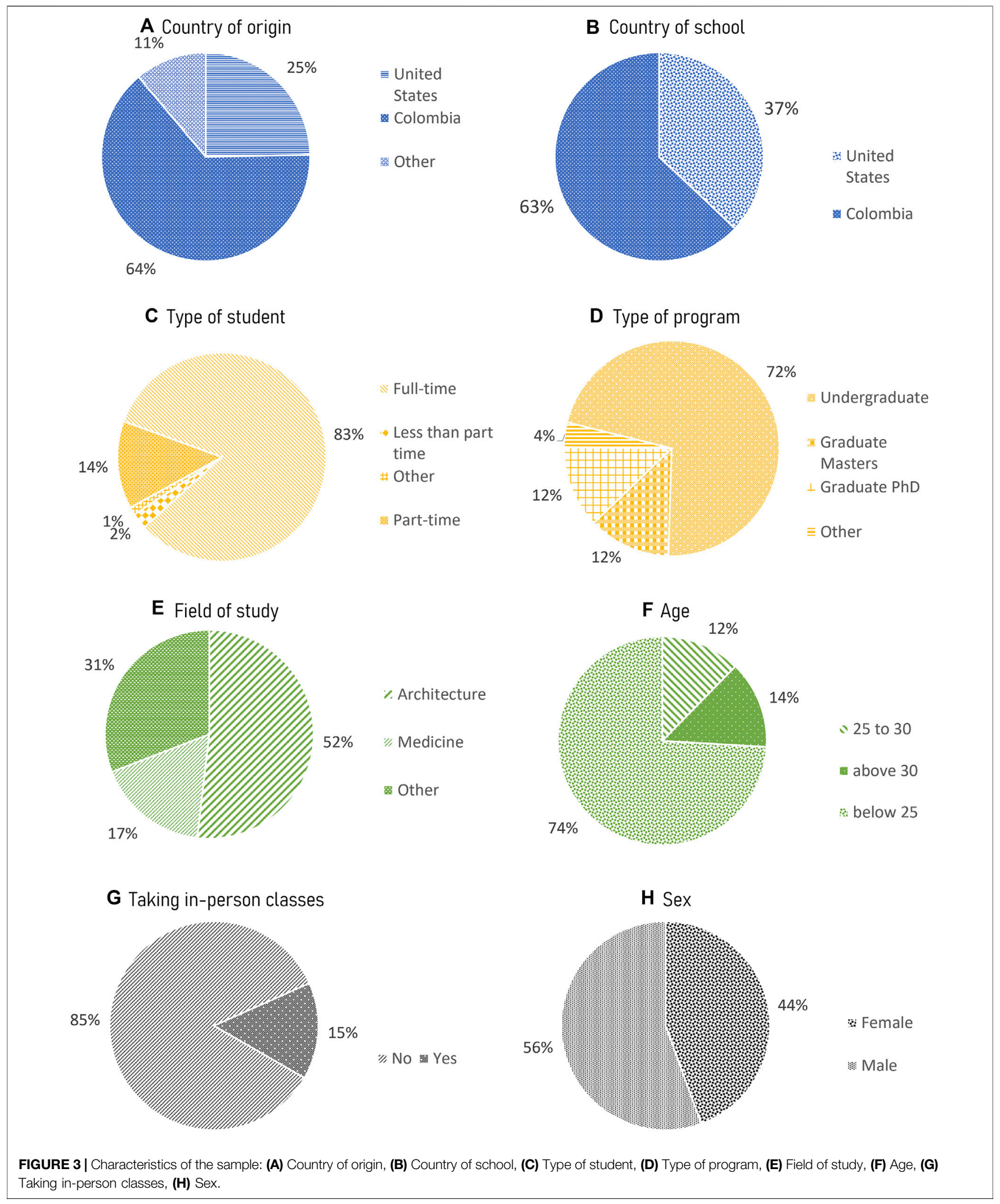




\section{Risk perceptions of students in the United States}

\section{(1) Visual connection to the outdoors}

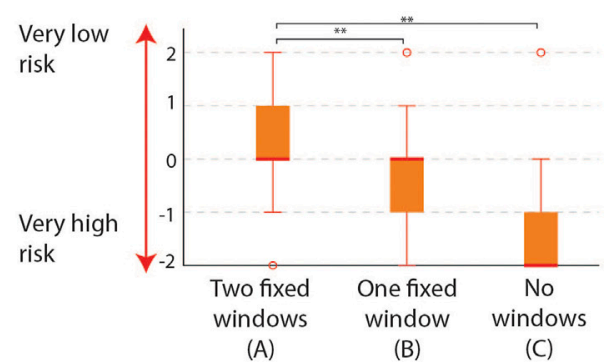

\section{(2) Reduced Occupancy}

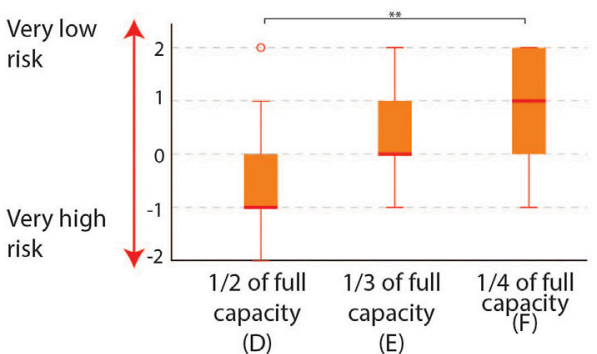

\section{(3) Added furnishings}

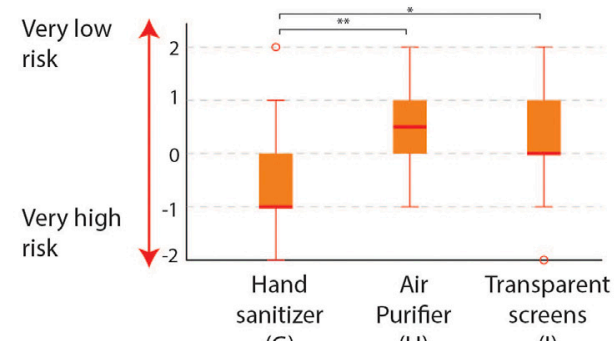

(G)

(H) (I)

(4) Ventilation type and number of operable windows

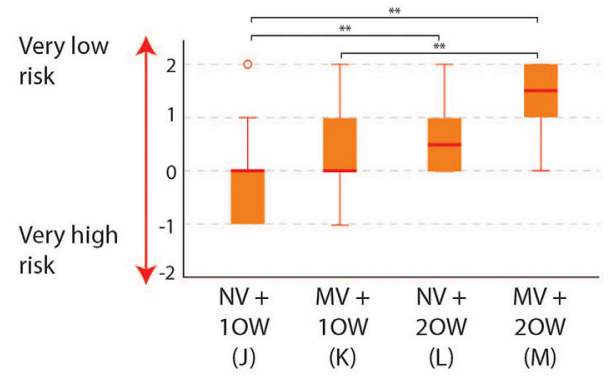

Risk perceptions of students in Colombia

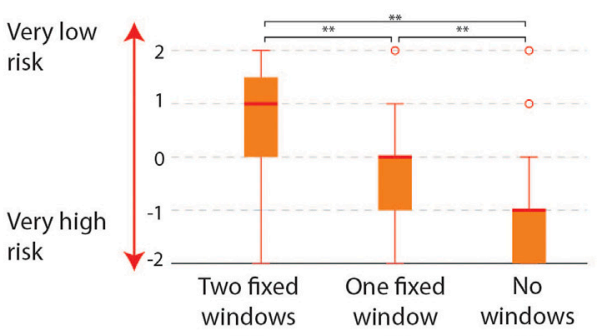

(A)

(B)

(C)

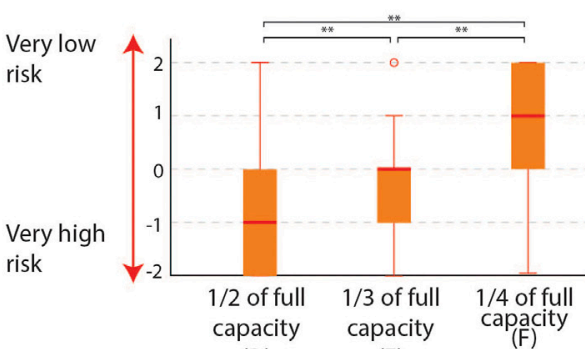

(D)

(E)

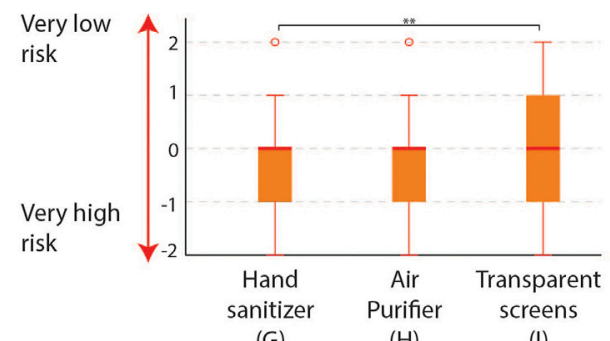

(G)

(H)

(I)

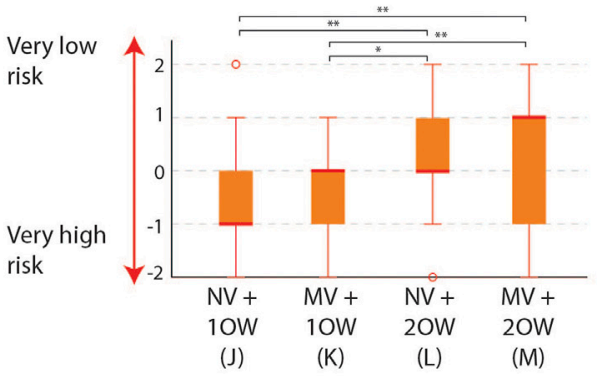

Key: NV: Natural Ventilation, MV: Mechanical Ventilation, OW: Operable Windows ${ }^{*} p<0.05$, ${ }^{* *} p<0.01$

FIGURE 4 | Significant differences between scenarios in each category in the United States. Significant differences noted with brackets within each graphic. ${ }^{\star}$ represents $p<0.01,{ }^{*}$ represents $p<0.05$. NV = Natural Ventilation, MV = Mechanical Ventilation, OW = Operable Windows. 


\section{Health promotion perceptions of students in the United States}

\section{Health promotion perceptions of students in Colombia}

\section{(1) Visual connection to the outdoors}
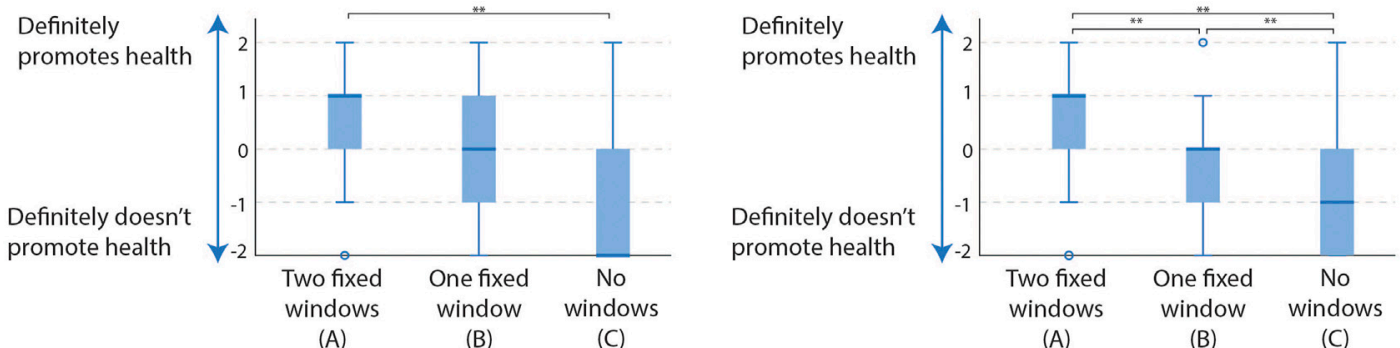

(A)

(B)

(C)

(2) Reduced Occupancy
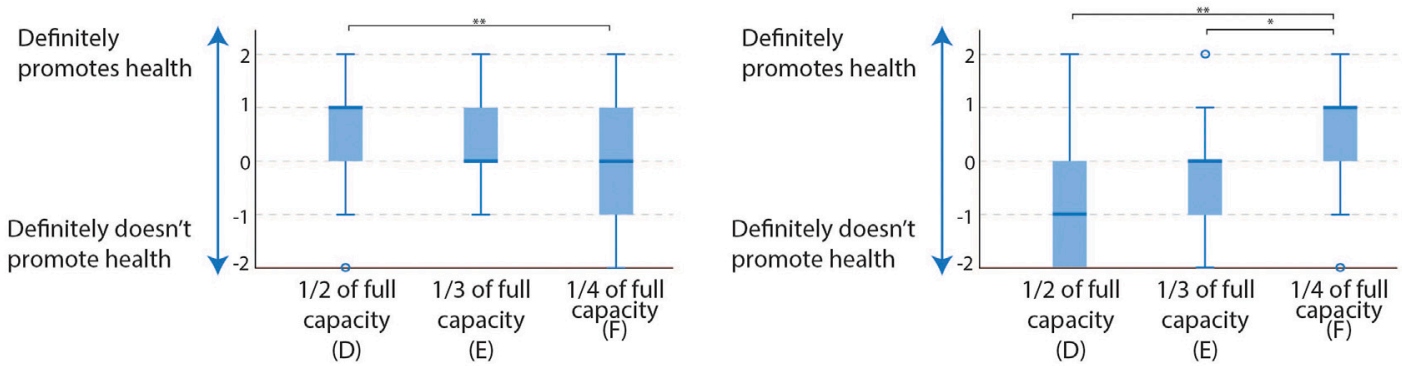

(D)

(E)

\section{(3) Added furnishings}
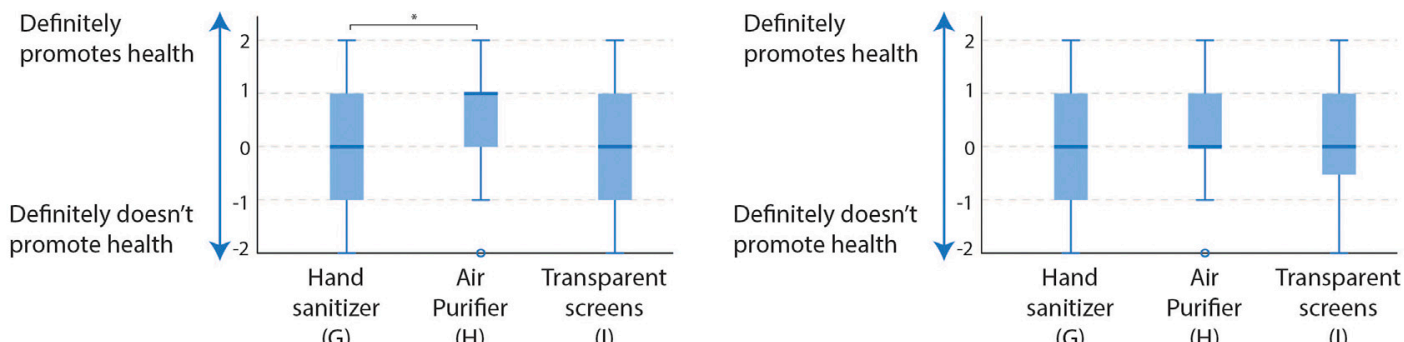

(4) Ventilation type and number of operable windows
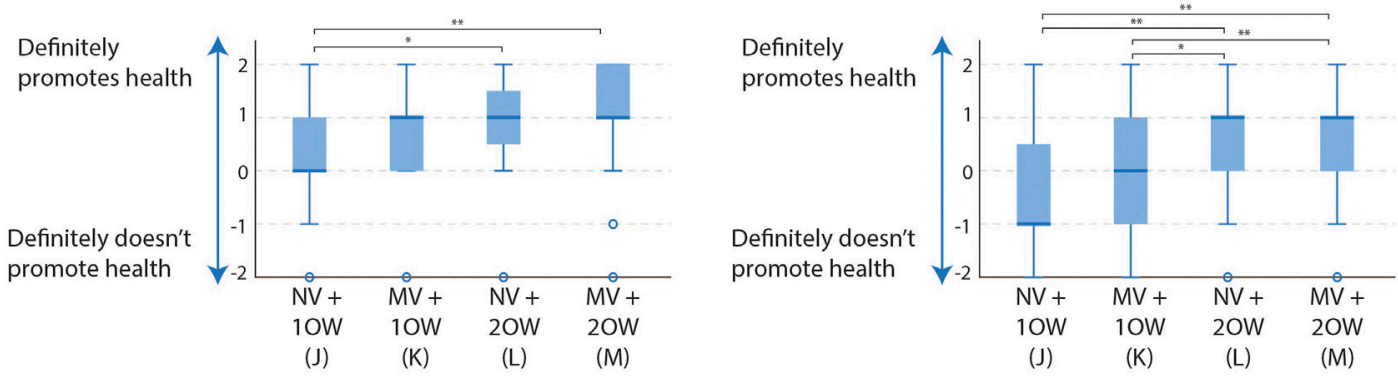

Key: NV: Natural Ventilation, MV: Mechanical Ventilation, OW: Operable Windows ${ }^{*} p<0.05$, ** $p<0.01$

FIGURE 5 | Significant differences between scenarios in each category in Colombia. Significant differences noted with brackets within each graphic. ${ }^{\star \star}$ represents $p<0.01,{ }^{*}$ represents $p<0.05$. NV = Natural Ventilation, MV = Mechanical Ventilation, OW = Operable windows. 
TABLE 1 | Median Ranks of each scenario for health risks and health promotion perceptions in the United States and Colombia.

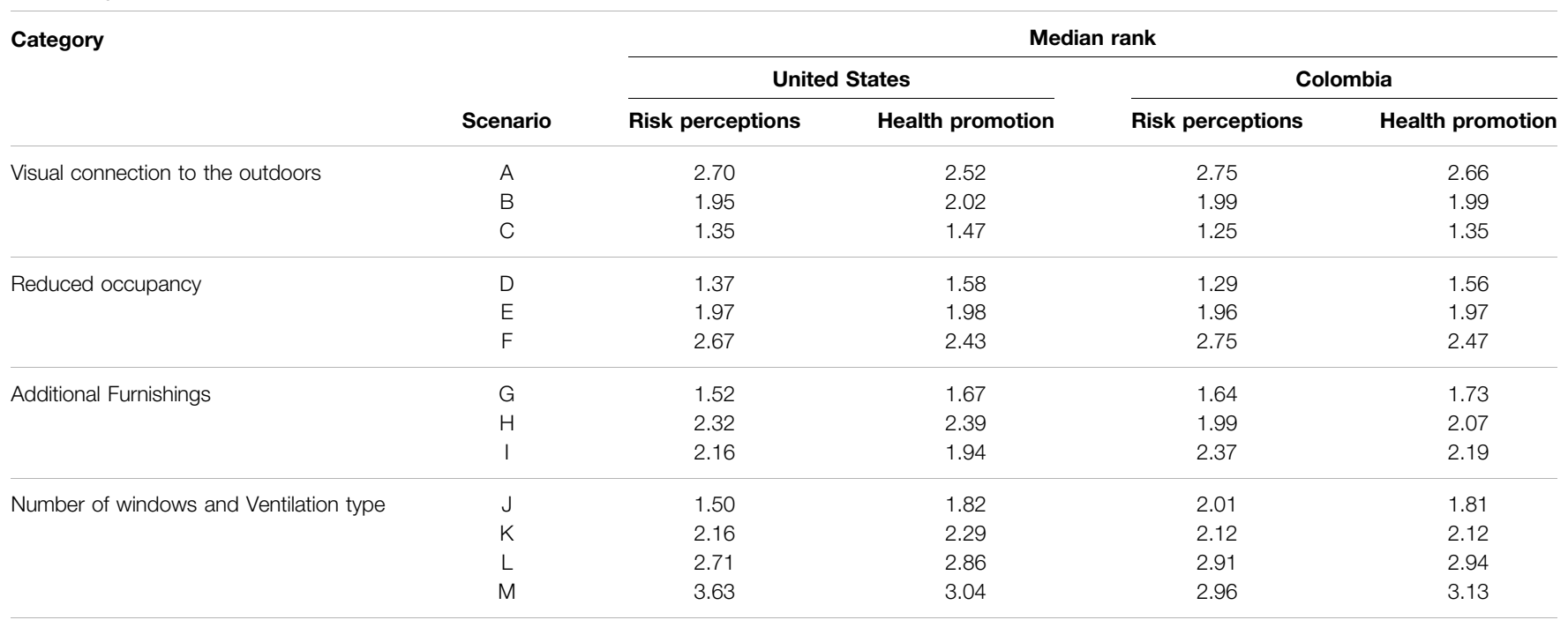

questions, the scale rated the strategies from "Not so important" to "Very important," but in this case, answers were coded $(1,2,3$, $4,5)$, with five being the highest importance score and one being the lowest. The structure of the survey is synthesized in Figure 2.

The data from the Spanish and English surveys was coded and collapsed into a single database to develop the statistical analysis. The data was analyzed within each country separately, as well as contrasting both countries using SPSS Statistics 26. All questions were analyzed using similar procedures. First, Friedman tests were used to assess the differences between the scenarios of each category independently for each country. Further pairwise comparisons adjusted with Bonferroni corrections revealed where these differences were occurring. Later, the scores of each scenario were compared between countries using MannWhitney tests to find differences in perceptions of specific strategies.

\section{RESULTS}

A total of 91 questionnaires were collected for the survey. Questionnaires that weren't filled by the target population or left blank were discarded. Questionnaires where most questions were answered were kept, but the analysis was adjusted in the questions that were left blank. A final sample of 81 responses from Colombia (63\%) and the United States (37\%) was considered for the study. Regarding country of origin, $64 \%$ of the respondents were originally from Colombia, $25 \%$ came from the United States, and $11 \%$ from other countries.

From this population, $83 \%$ of respondents were full-time students, $14 \%$ were part-time students, and the remaining $3 \%$ had a different status. The sample was balanced by sex, with $44 \%$ of the respondents being female and $56 \%$ being male. Undergraduate students accounted for $72 \%$ of the sample, Master students accounted for $12 \%$ and $\mathrm{Ph} . \mathrm{D}$. students for $12 \%$. At the time of this survey, $4 \%$ of students in the sample were enrolled in a different kind of program. Most students were younger than 25 years old (74\%), while fewer were 25 -30 years old $(12 \%)$ and above 30 years old (14\%). Respondents came mainly from schools of architecture (52\%), medicine (17\%), and other fields (31\%). Only 15\% of the respondents reported taking classes with some in-person activities. All the characteristics of the sample are detailed in Figure 3.

\section{Health Risk and Health Promotion Perceptions Within Each Country}

The differences in perceptions between scenarios in each category were assessed using Friedman tests, followed by pairwise comparisons using the Bonferroni correction. All significant differences in risk perceptions within the scenarios in each category for each country are presented in Figure 4. Similarly, differences on health promotion perceptions are presented in Figure 5. All significant differences in both figures are noted with a single or double asterisk. Median ranks for the United States and Colombia are presented in Table $\mathbf{1 .}$

Regarding the scenarios assessing different degrees visual connection to the outdoors, there were significant differences in risk perceptions for the students attending school in the United States $\chi^{2}(2)=35.8, p<0.01$. Significant differences were found between scenarios $(C)$ No windows and $(A)$ two fixed windows $(p<0.01)$; as well as between scenarios with (B) one fixed window and (A) Two fixed windows $(p<0.05)$. For Health promotion perceptions, there were significant differences between the three scenarios as well, $\chi^{2}(2)=21.6, p<0.01$. The pairwise comparisons showed significant differences between scenarios $(\mathrm{C})$ no windows and (A) two fixed windows $(p<0.01)$. In the case of students attending school in Colombia, significant differences in risk perceptions were also found regarding the three scenarios presented $\chi 2(2)=66.9, p<0.01$. The following pairwise comparisons revealed significant differences between all scenarios; (C) no windows, (B) one fixed window, or two fixed windows $(p<0.01)$, with scenario (A) two fixed windows resulting in the lowest risk ranking. For health promotion 
TABLE 2 | Mann-Whitney tests comparing scenarios between the United States and Colombia. Significance of $p<0.05$ is indicated with *

\begin{tabular}{|c|c|c|c|c|c|c|c|}
\hline \multirow[t]{2}{*}{ Category } & \multirow[t]{2}{*}{ Scenario } & \multicolumn{3}{|c|}{ Risk } & \multicolumn{3}{|c|}{ Health promotion } \\
\hline & & $\mathbf{n}$ & Mann-Whitney U & $\mathbf{Z}$ & $\mathbf{n}$ & Mann-Whitney U & $\mathbf{Z}$ \\
\hline \multirow[t]{3}{*}{ Visual connection to the outdoors } & A & 81 & 942.0 & 1.798 & 81 & 785.5 & 0.209 \\
\hline & $\mathrm{B}$ & 81 & 877.0 & 1.183 & 81 & 728.5 & -0.373 \\
\hline & C & 81 & 788.0 & 0.245 & 81 & 805.0 & 0.416 \\
\hline \multirow[t]{3}{*}{ Reduced occupancy } & $\mathrm{D}$ & 81 & 557.5 & -2.117 & 81 & 600.5 & -1.659 \\
\hline & $E$ & 81 & 617.5 & -1.532 & 81 & 602.5 & -1.663 \\
\hline & $\mathrm{F}$ & 81 & 696.0 & -0.705 & 81 & 696.5 & -0.694 \\
\hline \multirow[t]{3}{*}{ Additional Furnishings } & G & 80 & 685.5 & -0.570 & 80 & 741.5 & 0.210 \\
\hline & $\mathrm{H}$ & 77 & $478.0^{\star}$ & -2.312 & 74 & $462.5^{\star}$ & -2.031 \\
\hline & 1 & 77 & 716.0 & 0.330 & 74 & 684.0 & 0.579 \\
\hline \multirow[t]{4}{*}{ Number of windows and Ventilation type } & $J$ & 80 & 609.5 & -1.375 & 80 & $531.0^{\star}$ & -2.147 \\
\hline & $\mathrm{K}$ & 78 & 434.0 & -2.946 & 77 & $432.0^{\star}$ & -2.809 \\
\hline & $\mathrm{L}$ & 77 & $546.0^{\star}$ & -1.572 & 77 & 552.5 & -1.505 \\
\hline & $M$ & 78 & $338.0^{\star}$ & -3.927 & 77 & 556.5 & -1.458 \\
\hline
\end{tabular}

perceptions, there were also significant differences between all the scenarios presented, $\chi^{2}(2)=63.64, p<0.001$. All pairwise comparisons rendered a significance of $p<0.01$.

For reduced occupancy, in the case of students in the United States, there were significant differences in the three scenarios regarding risk perception $\chi^{2}(2)=32.8, p<0.01$. Following pairwise comparisons with the Bonferroni correction revealed significant differences only between scenarios showing the largest and smallest classroom occupancy (D) $1 / 2$ of its capacity and (F) $1 / 4$ of its capacity $(p<0.01)$. Significant differences also occurred for health promotion perceptions $(\chi 2(2)=20.7, p<0.01)$ in the same two scenarios. For respondents attending school in Colombia, there were also significant differences in risk perceptions $\chi^{2}(2)=$ 61.7, $p<0.01$, for the three occupancy scenarios. Further pairwise comparisons revealed significant differences between all classroom occupancy scenarios; scenario (D) $1 / 2$ of its capacity, (E) $1 / 3$ of its capacity, and (F) $1 / 4$ of its capacity $(p<0.01$ ), with scenario (D) $1 / 2$ of its capacity rendering the highest risk perceptions. For health promotion perceptions, the test also rendered significant differences $\chi^{2}(2)=32.6, p<0.01$. Following pairwise comparisons showed significant differences between scenario (D) $1 / 2$ of its capacity and (F) $1 / 4$ of its capacity $(p<0.01)$, as well as (E) $1 /$ 3 of its capacity and (F) $1 / 4$ of its capacity $(p<0.05)$.

In the scenarios with added furnishings, for students in the United States, significant differences were found between the scenarios $\chi^{2}(2)=15.75, p<0.01$ for risk perceptions. Pairwise comparisons revealed that these differences were present between scenarios $(\mathrm{G})$ hand sanitizer and (I) transparent screens $(p<0.05)$, as well as between $(\mathrm{G})$ hand sanitizer and $(\mathrm{H})$ air purifier $(p<0.01)$. Significant differences were also found regarding health promotion perceptions $\chi^{2}(2)=12.29, p<0.05$, between scenarios $(\mathrm{G})$ hand sanitizer and $(\mathrm{H})$ air purifier. For students in Colombia, significant differences were found for health risk perceptions $\chi^{2}(2)=18.28, p<$ 0.01 , only occurred between scenarios $(G)$ hand sanitizer and (I) transparent screens $(p<0.01)$. No significant differences were found for health promotion perceptions.

Finally, for ventilation types and number of windows, there were significant differences between the scenarios presented for risk perceptions of participants studying in the United States $\chi^{2}$ (3) $=54.10, p<0.01$. Pairwise comparisons revealed that these differences were located between scenarios with a different number of windows $(p<0.01)$, in all cases but between scenarios (K) $\mathrm{MV}+1 \mathrm{OW}$ and (L) NV+2OW. For Health promotion perceptions, there were also significant differences between scenarios $\chi^{2}(3)=27.95, p<0.01$. These differences only occurred between scenarios (J) NV+1 OW and (M) MV $+2 \mathrm{OW}$ $(p<0.01)$, and (J) NV+1 OW and (L) NV+2 OW $(p<0.05)$. For scenarios with the same number of windows, those with $\mathrm{MV}+$ OW rendered lower risk perceptions than those with $\mathrm{NV}+\mathrm{OW}$, both for health promotion and risk perceptions. For participants taking classes in Colombia, significant differences for risk perceptions scenarios $\chi^{2}(3)=28.00, p<0.01$ were found. Following pairwise comparisons revealed that these differences occurred between scenarios with different numbers of windows, regardless of the ventilation system $(p<0.01)$. For health promotion perceptions, there were also significant differences $\chi^{2}(3)=56.36, p<0.01$, which followed the same pattern. Similar to the United States, the scenarios that showed the additional features of MV had higher median rankings, only when comparing scenarios with the same number of windows.

\section{Health Risk and Health Promotion Perception Contrast Between Countries}

In order to understand the differences in perceived risk and health promotion between countries, independent samples Mann-Whitney tests were performed to each of the 12 scenarios using the country of school as a grouping variable. Incomplete answers were removed from the comparison. The results of these tests are summarized in Table 2 .

In the category of visual connection to the outdoors, there were no significant differences in perceptions between students attending school in Colombia or in the United States. Regarding reduced occupancy, in health risk perceptions, scenario (D) displaying a classroom with $1 / 2$ of its occupancy rendered significant differences between risk perceptions in the 2 countries $(p<0.05)$. The risk perception scores for the 
TABLE 3 | * Pairwise comparisons adjusting significance with a Bonferroni correction for eight hazard mitigation strategies at the $p<0.05$ level for students in the United States. Bold values are highlighted to indicate significance.

\begin{tabular}{|c|c|c|c|c|c|c|c|c|}
\hline United States & $\begin{array}{c}\text { Mechanical } \\
\text { ventilation }\end{array}$ & $\begin{array}{c}\text { Natural } \\
\text { ventilation }\end{array}$ & $\begin{array}{c}\text { Air } \\
\text { purifier }\end{array}$ & $\begin{array}{c}\text { Hand } \\
\text { sanitizer }\end{array}$ & $\begin{array}{c}\text { Transparent } \\
\text { screen }\end{array}$ & $\begin{array}{c}\text { Clean } \\
\text { surfaces }\end{array}$ & Mask & $\begin{array}{c}\text { Reduced } \\
\text { occupation }\end{array}$ \\
\hline $\begin{array}{l}\text { Mechanical } \\
\text { ventilation }\end{array}$ & 1.000 & & & & & & & \\
\hline Natural ventilation & -1.617 & 1.000 & & & & & & \\
\hline Air purifier & 0.767 & $2.383^{\star}$ & 1.000 & & & & & \\
\hline Hand sanitizer & 0.700 & $2.317^{\star}$ & -0.067 & 1.000 & & & & \\
\hline Transparent screen & $2.183^{\star}$ & $3.800^{\star}$ & 1.417 & 1.483 & 1.000 & & & \\
\hline Clean surfaces & -0.550 & 1.067 & -1.317 & -1.250 & $-2.733^{\star}$ & 1.000 & & \\
\hline Mask & -1.233 & 0.383 & $-2.000^{\star}$ & -1.933 & $-3.417^{\star}$ & -0.683 & 1.000 & \\
\hline Reduced occupancy & -0.783 & 0.833 & -1.550 & -1.483 & $-2.967^{\star}$ & -0.233 & 0.450 & 1.000 \\
\hline
\end{tabular}

* Indicates significant results at $p<0.05$

United States (mean rank $=47.92$ ) were statistically significantly higher than for Colombia (mean rank $=36.93$ ), $p=0.034$. The calculated effect size of this differences was $\eta^{2}=0.06$, meaning that only $6 \%$ of the variance between the scores can be explained by the difference in country of school.

In the category of additional furnishings, perceptions of students in the two countries showed significant differences in scenario $(\mathrm{H})$ air purifier for both perceptions of health risk, and perceptions of health promotion. For health risk perceptions, scores in the United States (mean rank $=46.43$ ) were significantly higher than scores in Colombia (mean rank $=34.76$ ), $p=0.021, \eta$ ${ }^{2}=0.07$. For health promotion perceptions, the United States had significantly higher scores (mean rank $=43.87$ ) than Colombia (mean rank $=33.84$ ), $p=0.042, \eta^{2}=0.06$. In this way, in the United States, perceptions of adding an air purifier in the classroom were significantly more positive regarding reduction of risk and promotion of health than in Colombia. Nonetheless, the effect size was small in both cases.

Finally, in the category of ventilation type and number of operable windows, risk perceptions were significantly different in scenarios (K) MV+ $1 \mathrm{OW}$ and (M) MV $+2 \mathrm{OW}$. For scenario (K) $p=0.003, \eta^{2}=0.11$, and the scores in the United States (mean rank $=48.07)$ were significantly higher than scores in Colombia (mean rank $=33.82)$. For scenario $(\mathrm{M})$, the tests rendered a $p<$ $0.001, \eta^{2}=0.2$. Scores in the United States (mean rank $=52.43$ ) were significantly higher than scores in Colombia (mean rank = 32.26). The effect sizes in both scenarios were small.

Health promotion was significantly different in scenarios (J) natural ventilation and one operable window, and $(\mathrm{K})$ mechanical ventilation and one operable window. In scenario in scenario (J) health promotion perceptions ranked significantly higher in the United States (mean rank $=47.69$ ) than in Colombia (mean rank $=36.41), p=0.032, \eta^{2}=0.06$. Similarly, in scenario K), health promotion perceptions were also significantly higher in the United States (mean rank $=48.07$ ) than in Colombia (mean rank $=33.82), p=0.005, n^{2}=0.10$.

\section{Importance Given to Physical Features to Mitigate Hazard Within Each Country}

For the second part of the survey, participants were asked to rate the importance of 8 hazard mitigation strategies on a Likert-scale from 1 to 5. In this case, there were no graphic aids. The strategies given to the participants were mechanical ventilation, natural ventilation, air purifier, hand sanitizer, transparent screen, clean surfaces, masks, and reduced occupancy.

A Friedman test found significant differences between the strategies for students attending school in the United States $\chi^{2}$ (7) $=69.92, p<0.01$. Following pairwise comparisons using Bonferroni, revealed that these differences existed between transparent screens and mechanical ventilation, natural ventilation, clean surfaces, masks, and reduced occupancy; between natural ventilation and air purifier and hand sanitizer; and between masks and air purifier. All significant differences are summarized in Table 3.

A similar procedure was developed to assess differences between the eight strategies for students taking classes in Colombia. A Friedman test found that significant differences existed $\chi^{2}(7)=92.72, p<0.01$. The following pairwise comparisons revealed that in Colombia, these differences were between transparent screens and natural ventilation, clean surfaces, masks, and reduced occupancy; between air purifier and clean surfaces, masks, natural ventilation and reduced occupancy; between natural ventilation and mechanical ventilation, air purifier and hand sanitizer; and finally, between masks and mechanical ventilation, air purifier and hand sanitizer. All significant differences are summarized in Table 4 .

\section{Importance Given to Physical Features Contrast Between Countries}

To understand the differences in the importance given to each strategy given by students in the United States and Colombia, independent samples Mann-Whitney tests were performed to each of the 8 strategies presented in the second set of questions. Significant differences were found between the importance given to transparent screens $\left(p<0.01, \eta^{2}=0.16\right)$. The scores for transparent screens in Colombia (mean rank $=47.94$ ) were significantly higher than in the United States (mean rank = 29.20). Significant differences were also found in the perceived importance of cleanliness $\left(p<0.01, \eta^{2}=0.10\right)$, where scores in Colombia (mean rank $=45.77$ ) were significantly higher than in the United States (mean rank = 32.88). The results of these tests are summarized in Table 5. 
TABLE 4 | Pairwise comparisons adjusting significance with a Bonferroni correction for eight hazard mitigation strategies at the $p<0.05$ level for students in Colombia. Bold values are highlighted to indicate significance.

\begin{tabular}{|c|c|c|c|c|c|c|c|c|}
\hline Colombia & $\begin{array}{c}\text { Mechanical } \\
\text { ventilation }\end{array}$ & $\begin{array}{c}\text { Natural } \\
\text { ventilation }\end{array}$ & $\begin{array}{c}\text { Air } \\
\text { purifier }\end{array}$ & $\begin{array}{c}\text { Hand } \\
\text { sanitizer }\end{array}$ & $\begin{array}{c}\text { Transparent } \\
\text { screen }\end{array}$ & $\begin{array}{c}\text { Clean } \\
\text { surfaces }\end{array}$ & Mask & $\begin{array}{c}\text { Reduced } \\
\text { occupation }\end{array}$ \\
\hline $\begin{array}{l}\text { Mechanical } \\
\text { ventilation }\end{array}$ & 1.000 & & & & & & & \\
\hline Natural ventilation & $-1.578^{\star}$ & 1.000 & & & & & & \\
\hline Air purifier & 0.696 & $2.275^{\star}$ & 1.000 & & & & & \\
\hline Hand sanitizer & 0.059 & $1.637^{\star}$ & -0.637 & 1.000 & & & & \\
\hline Transparent screen & 0.569 & $2.147^{\star}$ & -0.127 & 0.510 & 1.000 & & & \\
\hline Clean surfaces & -1.324 & 0.255 & $-2.02^{\star}$ & -1.382 & $-1.892^{*}$ & 1.000 & & \\
\hline Mask & $-1.843^{\star}$ & -0.265 & $-2.539^{\star}$ & $-1.902^{\star}$ & $-2.412^{\star}$ & -0.520 & 1.000 & \\
\hline Reduced occupancy & -1.206 & 0.373 & $-1.902^{*}$ & -1.265 & $-1.775^{\star}$ & 0.118 & 0.637 & 1.000 \\
\hline
\end{tabular}

* Indicates significant results at $p<0.05$

TABLE 5 | Mann-Whitney tests comparing scenarios between the United States and Colombia. Significance of $p<0.05$ is indicated with *. Bold values are highlighted to indicate significance.

\begin{tabular}{lccc}
\hline Scenario & \multicolumn{3}{c}{ Importance } \\
\cline { 2 - 4 } & $\mathbf{n}$ & Mann-Whitney U & $\mathbf{Z}$ \\
\hline Mech. Vent. & $\mathbf{8 1}$ & 785.0 & 0.206 \\
Nat. Vent. & $\mathbf{8 1}$ & 817.5 & 0.723 \\
Air Purifier & $\mathbf{8 1}$ & 772.5 & 0.077 \\
Hand Sanitizer & $\mathbf{8 1}$ & 895.0 & 1.326 \\
Tr. Screens & $\mathbf{8 1}$ & $1,119.0^{\star}$ & 3.549 \\
Cleanliness & $\mathbf{8 1}$ & $1,008.5^{\star}$ & 2.782 \\
Masks & $\mathbf{8 1}$ & 887.5 & 1.876 \\
Red. Occupancy & $\mathbf{8 1}$ & 880.0 & 1.335 \\
\hline
\end{tabular}

* Indicates significant results at $p<0.05$

Since the open-ended question was optional, it was only used to gather additional information. A total of 13 respondents included comments, which are no included in the analysis but inform the discussion in the following section.

\section{DISCUSSION}

\section{Perceived Health Risk \& Health Promotion}

A comparison between different degrees of visual connections to the outdoors revealed that an increase in the number of windows in a classroom generated lower perceptions of risk and increased those of health promotion. The three classroom scenarios in this category featured fixed windows and mechanical ventilation, so they would behave similarly regarding IAQ. This did not seem to be the factor determining students' perceptions.

The differences in perceptions imply that a visual connection to the outdoors has an impact on students' perception of a healthy space. Similar implications have been observed in experimental studies, where having a window has been found to improve psychological wellbeing by enhancing positive emotions and reducing negative ones (Ko et al., 2020). Windows are related to visual connections to nature (Ko et al., 2020), which can have a positive impact on attention restoration, stress reduction, and positive emotions (Capaldi et al., 2014; Lumber et al., 2017), as well as in health and wellbeing (Ko et al., 2020). It seems plausible that the visual connection to the outdoors is related to ideas of open spaces and ventilation, and therefore perceived as healthier during the pandemic. Nonetheless, this needs further investigation.

Regarding risk perceptions, in the United States, significant differences didn't occur between the scenario with one fixed window and the scenario with no window. Nonetheless, the value was close to significance $(p=0.06)$. On the other hand, for students in Colombia, significant differences were present between all scenarios. Regarding health promotion perceptions, in the United States, significant differences only occurred between scenarios with 2 windows and no windows, while in Colombia differences occurred between all scenarios. It appears that for students in Colombia, an increased amount of visual connection to the outdoors produces more significantly different perceptions regarding health risk and health promotion than for students in the United States. Nonetheless, when assessing the differences of each scenario between the two countries, no significant differences were found.

Regarding reduced occupancy, the statistical differences in perceptions revealed that participants preferred classrooms with fewer students. After a year of taking classes online, the results showed an awareness of physical distancing guidelines to prevent the spread of viral transmission, which aligns with current recommendations (Bak et al., 2021). This finding may be interesting to educational institutions, as their students may feel safer working in classrooms with smaller groups or lower student densities. It also points to a change in behavior, and a transition in how building spaces are inhabited and used after returning to in-person activities that promote perceptions of health promotion and reduce risk in enclosed indoor spaces.

For students attending the university in the United States, risk perceptions rendered significant differences between $1 / 2$ and $1 / 4$ of the occupancy of the classrooms. For students in Colombia, significant differences occurred in all scenarios of risk perception. These results show that students in Colombia appeared to be more sensitive to occupancy changes in classrooms than students in the United States. Regarding health promotion, for students in the United States there were significant differences in perceptions only between the two extreme occupancy scenarios. In Colombia, these differences only failed to occur in the scenarios with $1 / 2$ and 
$1 / 3$ of occupancy. When looking at significant differences in the three scenarios between the 2 countries, there was a significant difference in scenario (D) for students in Colombia, meaning that these students perceived significantly higher risk in a classroom with half the occupancy, compared to students in the United States. This result supports the previous finding and reinforces the idea that for students in Colombia, differences in classroom occupancy were an important aspect driving positive perceptions related to health when the survey was administered.

For additional furnishings in classrooms, the statistical differences between the three furnishings assessed showed that hand sanitizer produced higher perceived risk and lower perceived health promotion compared to the other two strategies. No significant differences were found between health risk perceptions of transparent screens and the use of an additional air purifier in the United States or Colombia. This finding is interesting because transparent screens were dropped as a recommendation by the United States CDC in schools on March 19, 2021 (Centers for Disease Control, 2021a), while air purifiers can use high-efficiency filters to improve IAQ, and are still being promoted as an effective strategy.

The furnishing strategy that rendered lower risk perceptions varied by country. In Colombia, it was transparent screens, while in the United States, it was air purifiers. For students in the United States, significant differences in risk perceptions occurred between hand sanitizer and air purifiers, as well as between hand sanitizer and transparent screens. In Colombia, significant differences only occurred between hand sanitizer and transparent screens. It may be that the information recently provided by the CDC had an influence on perceptions in the United States, while in Colombia, students still preferred having physical barriers over adding air purifiers. In addition, in Colombia, mechanical ventilation and efficient air purifiers are not commonplace in every city, so it is possible that a lack of familiarity with this type of technology generated lower scores than in the United States.

Regarding health promotion perceptions, in Colombia, there were no significant differences between the three classroom scenarios. In the United States, there were only differences between hand sanitizer and air purifiers, with the scores for air purifiers being significantly higher. Therefore, it appears that the furnishings more associated with perceptions of health promotion in the United States were air purifiers. When looking at differences between countries in the three furnishing scenarios, significant differences were found in the scenario showing an air purifier. Perceptions of students in the U.S presented significantly higher scores for both risk and health promotion, meaning that they had significantly more positive perceptions in this scenario than students in Colombia.

Regarding the number of windows and ventilation types, the two scenarios with only one operable window ( $\mathrm{J}$ and $\mathrm{K}$ ) rendered the lower mean rank scores for risk and health promotion perceptions in the two countries. No significant differences were found between them in either assessment. Similarly, the two scenarios with two windows ( $\mathrm{L}$ and $\mathrm{M}$ ) showed no significant differences between them for risk or health promotion perceptions in either country. The scores of risk perceptions and health promotion were lower for the scenarios with natural ventilation in both countries. All significant differences in pairwise comparisons were found between scenarios with one window vs. scenarios with two windows. Similar to what happened in the first category, it appears that the number of windows in the classroom was driving the perceptions more than the type of ventilation.

For ventilation type and the number of windows in Colombia, the scenarios with one window showed significant differences when compared to the scenarios with two windows regarding risk perceptions, regardless of the ventilation system used. In Colombia, mechanical ventilation is not as common as it is in the United States. Therefore, the lack of influence of the ventilation type in students' perceptions of health risk may be due to a lack of familiarity with the filtration capabilities of these systems. On the other hand, since most buildings in Colombia are naturally ventilated, students may associate the increase in operable windows with increased airflow, regardless of the ventilation system. In the United States significant differences occurred between scenarios with the same ventilation system and different numbers of windows, as well as between the scenario with $1 \mathrm{OW}+\mathrm{NV}$ and the scenario with $2 \mathrm{OW}+\mathrm{MV}$. When comparing the 4 scenarios between the 2 countries for risk perception, significant differences occurred in the 2 scenarios with mechanical ventilation ( $\mathrm{K}$ and $\mathrm{M}$ ). In Colombia scores were significantly lower, meaning that students would feel significantly higher risk in classrooms with mechanical ventilation than students in the United States, which supports the previous finding. Future studies could further investigate the associations between the prevalent ventilation system and health risk perceptions in architectural spaces.

Regarding health promotion perceptions, in the United States, significant differences occurred between the scenarios with one operable window and natural ventilation, and the two scenarios with two windows, regardless of ventilation system. For Colombia, health promotion perceptions showed the same pattern as risk perceptions, where the differences occurred between scenarios with a different number of windows, regardless of the ventilation system. This aligns with the previous finding and reveals that at the time of the survey in Colombia, changes in the built environment produced wider changes in perceptions towards health than in the United States. Finally, when comparing the health promotion between the 2 countries, significant differences occurred in the 2 scenarios that showed only one window, where Colombia showed lower scores. Therefore, students in Colombia felt significantly less health promotion in the scenarios with a single window.

\section{Perceived Importance of Different Hazard Mitigation Strategies}

In Colombia, the proper use of masks obtained the highest mean rank, followed by natural ventilation. In the United States, natural ventilation obtained the highest score, followed by the proper use of masks. The middle range mean scores were strategies related to reduced occupancy, clean 
surfaces, and mechanical ventilation in both countries. Finally, at the bottom of the importance spectrum were hand sanitizer, air purifiers, and transparent screens.

The high importance given to natural ventilation and masks in the 2 countries may be because it is now widely accepted that COVID 19 is mainly transmitted through exposure to fluids that carry the virus. This transmission can happen through inhalation of fine droplets or aerosols, or the deposition of respiratory droplets in the mouth, nose or eyes after traveling through the air (Centers for Disease Control, 2021c). Also, the high importance given to masks reveals that even when PPE may not be the most effective control in the scale, it might provide a sense of security to students returning to in person classes.

The middle range strategies are more related to administrative controls. One interesting issue to note is that mechanical ventilation wasn't highly ranked in importance despite its higher position in the hierarchy of controls. One of the comments left by a respondent of the survey may shed some light on why this occurred. The respondent explained that students were usually unaware of the maintenance of the ventilation system of the school; therefore, they could not trust that it was working properly. It appears that good communication of the improvements made to mechanical ventilation systems to the student population may increase the reliability that students have in them.

Finally, furnishing strategies appear to be less important for students' perceptions of risk and health promotion when compared to occupancy reduction, and ventilation interventions. In Colombia, air purifiers received the lowest ranking, despite being a more effective strategy than transparent screens. This may be due to students being unfamiliar with the technology, which is not widespread in the country. Differently, in the United States transparent screens received the lowest scores, which aligns with the CDC mandates (Centers for Disease Control, 2021a).

When comparing student perceptions between the eight hazard mitigation strategies, the only major differences between the two countries were observed in the importance given to transparent screens and clean surfaces. Both strategies were ranked significantly higher in Colombia than in the United States. The differences in the importance of transparent screens align with the differences found on perceptions of health risk, where transparent screens in Colombia were highly valued in comparison with the other 2 furnishings presented.

\section{LIMITATIONS}

By assessing perceptions through an anonymous online survey, it was only possible to include visual and written cues for each risk mitigation strategy under consideration. In reality, the physical experience of a place has a multisensory character. Therefore, it is possible that other environmental parameters such as temperature, air quality, among others, modify health risk and health promotion perceptions. Repeating the survey in a field setting may result in different results or confounding factors.
Another limitation of the study has to do with the sample size and distribution. Students in the United States were mainly recruited from one higher education institution in the pacific northwest. In Colombia, students from two higher education institutions in the center and south of the country comprised most of the sample. Therefore, it is not possible to generalize the conclusions to a larger population. Nonetheless, the results are useful for higher education institutions returning to in-person activities as it offers an important snapshot in time of the end of the 2020-2021 school year. The results from this survey may also motivate additional research into risk and health promotion perceptions in a larger population.

Local differences in air quality and climate may have influenced the responses. The Pacific Norwest has moderate four seasons, which creates the need for heating and cooling during the winter and summer months. Colombia on the other hand, doesn't have seasons and cities have a steady climate during the whole year. Nonetheless, the two cities where sample came from are located at different altitudes, which makes their climates completely different, with averages of 13.3 and $27.7^{\circ} \mathrm{C}$. This factor may change the perceptions on the need for ventilation and the connection to the outdoors. In addition, the survey didn't ask for medical information of the respondents. Respiratory illness or allergies could affect users' perceptions of the space. A recent article pointed out that families of children with asthma perceived going back in-person schooling as being very risky for their children, even when there was no evidence that they were at increased risk of COVID-19 morbidity or mortality (Abrams et al., 2021). Nonetheless, this topic didn't arise in the additional comments.

Other variables that may modify perceptions of space were not included in the survey. For example, there was no mention of vaccination rates among the occupants of the classrooms presented in the images. A respondent commented that if the vaccination rate were $100 \%$, all the classrooms presented would be perceived as safe. The authors plan on repeating this same survey in the future, after vaccination has become more widespread. The results are expected to differ over time, as our proximity to acute risk changes. For this reason, this research only represents a snapshot in time of students' perceptions of classrooms before returning to in-person activities during the COVID-19 pandemic.

Another variable that was not included in the survey has to do with the duration of occupancy. The CDC guidelines for people who had contact with individuals known or suspected of having COVID19 considered exposures of $15 \mathrm{~min}$ or more (Centers for Disease Control, 2021b). It is possible that by including a time variable, some of the responses may have changed. The use of masks was included in the importance question, but not in the health risk and health promotion perceptions questions. In these questions, all occupants of the classrooms were portrayed using masks. Since the recommendation for masks in interior spaces have keep changing with vaccination status and the appearance of new variants of the virus, a future survey could explore health risk and health promotion perceptions, including mask use or lack of use.

This study only dealt with students in classrooms of higher education institutions. Similar studies could be performed in primary and secondary schools or in office buildings, to assess the 
perceptions of different populations on the same issues before or during reoccupation. Current approaches towards healthy buildings recognize the existence of a challenge in how to define a healthy building, and how to determine the best metric to assess it. Frameworks such as the Health Performance Indicators, propose quantifiable measures that can be used to identify triggers of positive and negative impacts on human health (J. G. Allen et al., 2015). Assessing perceptions on environmental health risks and health promotion after the pandemic may become one of these measures.

\section{CONCLUSION}

This study presented survey results for student perceptions of environmental health in relation to a range of physical risk mitigation strategies in classrooms between students in the United States and Colombia. Through an online survey using rendered images of $3 \mathrm{D}$ modelled classrooms and written cues, four categories (visual connection to the outdoors, reduced occupancy, additional furnishings, and ventilation type and number of windows) were evaluated among college students regarding health risks and health promotion perceptions. The importance given to a set of hazard mitigation strategies related to physical features of classrooms was evaluated as well.

For the visual connection to the outdoors category, significant differences occurred in scenarios with a different number of windows. Significant differences in perceptions also happened with every decrease in occupant density. In Colombia, transparent screens were more positively perceived, while in the United States, this happened with air purifiers. Hand sanitizer produced significantly lower perceptions of safety than the other furnishings. Finally, for the ventilation type and number of windows category, significant differences occurred in the scenarios with different numbers of windows. Perceptions seemed to be more driven by the number of windows than by the ventilation system.

Students in the two countries presented different perceptions of health risks and health promotion regarding some of the categories under evaluation. Perceptions of students taking classes in Colombia were more sensitive to changes in physical features of classrooms. As the two countries were in different stages of the COVID-19 pandemic in May 2021, and traditionally use different ventilation strategies, it is possible that these differences have an influence in student's perceptions. Repeating the study further in time may render some light on this issue.

Regarding the perceived importance of different physical features of the built environment to control hazards, natural ventilation and the use of masks presented the highest mean rankings. Mechanical ventilation did not present a high ranking, despite being one of the main strategies used to mitigate the virus in indoor environments. This may be explained by the fact that assessing the efficiency of the ventilation system of a classroom only through visual cues is not possible. It is necessary that building administrators inform students of their maintenance practices and educate them on the impacts, so that students can feel safe when returning to classrooms.
The results presented in this article shed light on aspects of the built environment that shaped perceptions of health risk and health promotion before the reoccupation of classrooms in the COVID-19 pandemic. The results presented here may help educational institutions structure their strategies to promote healthy classrooms for in-person classes. In addition, this study presented a unique snapshot of perceptions of the built environment for a moment in time during the pandemic in 2 countries. The differences found in the study portray how contextual differences may change the way building occupants perceive a given setting, even in a hypothetical situation. Future studies could further investigate the causes of these differences.

The study also unveiled existing issues in the way in which building occupants think of the mechanical systems in buildings. It appears that visual cues trigger assumptions about the degree of environmental health of a space. Therefore, providing information to the occupants on the upgrades made to the spaces and the capabilities of the systems to control the spread of the virus, especially during the pandemic, might help diminish the anxiety that health concerns might produce. After the pandemic, the reoccupation of buildings will have to go through a transition before normalizing again. It is important to include measures that will reinforce the physical, social, and mental wellbeing of students, by providing spaces that promote health and increase perceptions of safety in classrooms.

\section{DATA AVAILABILITY STATEMENT}

The raw data supporting the conclusions of this article will be made available by the authors, without undue reservation.

\section{ETHICS STATEMENT}

Ethical review and approval was not required for the study on human participants in accordance with the local legislation and institutional requirements. The patients/participants provided their written informed consent to participate in this study.

\section{AUTHOR CONTRIBUTIONS}

MC: Conceptualization, Methodology, Data Curation, Formal Analysis, Validation, Writing, Original Draft Preparation, Review \& Editing, Visualization. SR: Conceptualization, Methodology, Validation, Review \& Editing. AK: Validation, Review \& Editing.

\section{FUNDING}

This work is independent research with the support of two laboratories inside the School of Architecture and Environment of the University of Oregon. It did not receive any specific grant from funding agencies or commercial bodies. 


\section{REFERENCES}

Abrams, E. M., Shaker, M., and Greenhawt, M. (2021). School Attendance, Asthma Risk, and COVID-19 in Children. J. Allergy Clin. Immunol. Pract. 9 (6), 2145-2150. doi:10.1016/j.jaip.2021.03.006

Allen, J. G., MacNaughton, P., Laurent, J. G. C., Flanigan, S. S., Eitland, E. S., and Spengler, J. D. (2015). Green Buildings and HealthCurrent Environmental Health Reports. Curr. Envir Health Rpt 2 (Issue 3), 250-258. doi:10.1007/s40572-015-0063-y

Allen, J., Spengler, J., Jones, E., and Cedeno-Laurent, J. (2020). 5-step Guide to Checking Ventilation Rates in Classrooms. Available at: www.ForHealth.org.

Altomonte, S., Allen, J., Bluyssen, P. M., Brager, G., Heschong, L., Loder, A., et al. (2020). Ten Questions Concerning Well-Being in the Built Environment. Building Environ. 180, 106949. doi:10.1016/j.buildenv.2020.106949

Amundadottir, M. L., Rockcastle, S., Sarey Khanie, M., and Andersen, M. (2017). A Human-Centric Approach to Assess Daylight in Buildings for Non-visual Health Potential, Visual Interest and Gaze Behavior. Building Environ. 113, 5-21. doi:10.1016/j.buildenv.2016.09.033

ASHRAE (2020). Guidance for the Re-opening of Schools. Available at: https:// www.ashrae.org/file library/technical resources/covid-19/guidance-for-the-reopening-of-schools.pdf.

Awada, M., Becerik-Gerber, B., Hoque, S., O'Neill, Z., Pedrielli, G., Wen, J., et al. (2021). Ten Questions Concerning Occupant Health in Buildings during normal Operations and Extreme Events Including the COVID-19 Pandemic. Building Environ. 188, 107480. doi:10.1016/j.buildenv.2020.107480

Bak, A., Mugglestone, M. A., Ratnaraja, N. V., Wilson, J. A., Rivett, L., Stoneham, S. M., et al. (2021). SARS-CoV-2 Routes of Transmission and Recommendations for Preventing Acquisition: Joint British Infection Association (BIA), Healthcare Infection Society (HIS), Infection Prevention Society (IPS) and Royal College of Pathologists (RCPath) Guidance. J. Hosp. Infect. 114, 79-103. doi:10.1016/j.jhin.2021.04.027

Blume, H. (2021). Many LAUSD Students Won't Return to Campus, Early Survey Results Say - Los Angeles Times. Los Angeles Times. Available at: https://www.latimes.com/ california/story/2021-03-15/parents-worry-kids-in-school-bad-la-covid-areas.

Capaldi, C. A., ZelenskiDopko, J. M., and Zelenski, J. M. (2014). The Relationship between Nature Connectedness and Happiness: A Meta-Analysis. Front. Psychol. 5 (AUG), 1-15. doi:10.3389/fpsyg.2014.00976

Centers for Disease Control and The National Institute for Occupational Safety and Health (2013). "Indoor Environmental Quality," in Workplace Safety Health Topics. Available at: https://www.cdc.gov/niosh/topics/indoorenv/.

Centers for Disease Control (2020). K-12 Schools COVID-19 Mitigation Toolkit. Available at: https://www.cdc.gov/coronavirus/2019-ncov/community/.

Centers for Disease Control (2021a). Operational Strategy for K-12 Schools through Phased Prevention. Available at: https://www.cdc.gov/coronavirus/ 2019-ncov/community/schools-childcare/operation-strategy.html.

Centers for Disease Control (2021b). "Public Health Guidance for CommunityRelated Exposure," in COVID-19. Available at: https://www.cdc.gov/ coronavirus/2019-ncov/php/public-health-recommendations.html.

Centers for Disease Control (2021c). "Scientific Brief: SARS-CoV-2 Transmission," in COVID-19. Available at: https://www.cdc.gov/coronavirus/2019-ncov/ science/science-briefs/sars-cov-2-transmission.html?CDC_AA_refVal=https\% 3A\%2F\%2Fwww.cdc.gov\%2Fcoronavirus\%2F2019-ncov\%2Fscience\%2Fsciencebriefs\%2Fscientific-brief-sars-cov-2.html.

Danell, M., Ámundadóttir, M. L., and Rockcastle, S. (2020). Evaluating Temporal and Spatial Light Exposure Profiles for Typical Building Occupants. Symp. Simulation Architecture Urban Des., 539-546.

Dietz, L., Horve, P. F., Coil, D. A., Fretz, M., Eisen, J. A., Van Den Wymelenberg, K., et al. (2020). 2019 Novel Coronavirus (COVID-19) Pandemic: Built Environment Considerations to Reduce Transmission. mSystems 5. doi:10.1128/mSystems.00245-20

Ezarik, M. (2021). "Student Experiences during COVID and Campus Reopening Concerns," in Inside Higher ED. Available at: https://www. insidehighered.com/news/2021/03/24/student-experiences-during-covidand-campus-reopening-concerns.

Fischhoff, B., Slovic, P., Lichtenstein, S., Read, S., and Combs, B. (1978). How Safe Is Safe Enough? A Psychometric Study of Attitudes toward Technological Risks and Benefits. Pol. Sci. 9, 80-103. doi:10.1007/bf00143739
Han, Q., Zheng, B., Agostini, M., Bélanger, J. J., Gützkow, B., Kreienkamp, J., et al. (2021). Associations of Risk Perception of COVID-19 with Emotion and Mental Health during the Pandemic. J. Affective Disord. 284, 247-255. doi:10.1016/j.jad.2021.01.049

Healthy Buildings and Harvard T.H Chan School of Public Health (2020). 20 Questions to Ask before Sending Your Kids Back to School - Schools for Health. Available at: https://schools.forhealth.org/risk-reduction-strategies-forreopening-schools/faqs/(Accessed October 15, 2020).

International Energy Agency (IEA) (2017). Air Conditioner Sales Growth and Per Capita Sales in Selected Countries. Paris, France: World Energy Investment. Available at: https://vipo.iea.org/newsroom/energysnapshots/air-conditionersales-growth.html.

International Energy Agency (IEA) (2018). The Future of Cooling Opportunities for Energy- Efficient Air conditioning. France: IEA. Available at: www.iea.org.

Jones, E., Young, A., Clevenger, K., Salimifard, P., Wu, E., Lahaie Luna, M., et al. (2020). Schools for Health. Risk Reduction Strategies for Reopening Schools.

JRAIA (2019). "World Air Conditioner Demand by Region," in The Japan Refrigeration and Air Conditioning Industry Association. Available at: https://www.jraia.or.jp/english/World_AC_Demand.pdf.

Klepeis, N. E., Nelson, W. C., Ott, W. R., Robinson, J. P., Tsang, A. M., Switzer, P., et al. (2001). The National Human Activity Pattern Survey (NHAPS): A Resource for Assessing Exposure to Environmental Pollutants. J. Expo. Sci. Environ. Epidemiol. 11 (3), 231-252. doi:10.1038/si.jea.7500165

Ko, W. H., Schiavon, S., Zhang, H., Graham, L. T., Brager, G., Mauss, I., et al. (2020). The Impact of a View from a Window on thermal comfort, Emotion, and Cognitive Performance. Building Environ. 175, 106779. doi:10.1016/ j.buildenv.2020.106779

Lumber, R., Richardson, M., and Sheffield, D. (2017). Beyond Knowing Nature: Contact, Emotion, Compassion, Meaning, and beauty Are Pathways to Nature Connection. PLoS ONE 12, e0177186. doi:10.1371/ journal.pone. 0177186

Megahed, N. A., and Ghoneim, E. M. (2021). Indoor Air Quality: Rethinking Rules of Building Design Strategies in Post-pandemic Architecture. Environ. Res. 193, 110471. doi:10.1016/j.envres.2020.110471

National Academies of Sciences Engineering and Medicine (2020). Reopening K-12 Schools during the COVID-19 Pandemic: Prioritizing Health, Equity, and Communities. (Washington, DC: National Academies Press). doi:10.17226/25858

National Institute for Occupational Safety and Health (2015). Hierarchy of Controls. Available at: https://www.cdc.gov/niosh/topics/hierarchy/.

Ritchie, H., Mathieu, E., Rodés-Guirao, L., Appel, C., Giattino, C., Ortiz-Ospina, E., et al. (2021). "Coronavirus Pandemic (COVID-19)," in Our World in Data. Available at: https://ourworldindata.org/covid-vaccinations?country=USA.

The Center for Green Schools and ASHRAE. (2021). Preparation in the Pandemic: How Schools Implemented Air Quality Measures to Protect Occupants from COVID-19.

World Health Organization (2006). "WHO Constitution," in Basic Document Forthy. fifth edition (Issue January 1984). Available at: http://www.who.int/ governance/eb/who_constitution_en.pdf.

Conflict of Interest: The authors declare that the research was conducted in the absence of any commercial or financial relationships that could be construed as a potential conflict of interest.

Publisher's Note: All claims expressed in this article are solely those of the authors and do not necessarily represent those of their affiliated organizations, or those of the publisher, the editors and the reviewers. Any product that may be evaluated in this article, or claim that may be made by its manufacturer, is not guaranteed or endorsed by the publisher.

Copyright $\odot 2021$ Coronado, Rockcastle and Kwok. This is an open-access article distributed under the terms of the Creative Commons Attribution License (CC BY). The use, distribution or reproduction in other forums is permitted, provided the original author(s) and the copyright owner(s) are credited and that the original publication in this journal is cited, in accordance with accepted academic practice. No use, distribution or reproduction is permitted which does not comply with these terms. 